\title{
Discurso de Hipólito Yrigoyen del 16 de octubre de 1920
}

Ailén Díaz ${ }^{1}$

\author{
Universidad Nacional de La Plata - Argentina
}

Revista Derechos en Acción ISSN 2525-1678/ e-ISSN 2525-1686

Año 5/NNo 14, Verano 2019-2020 (21 diciembre a 20 marzo), 845-852

DOI: https://doi.org/10.24215/25251678e378

ORCID: https://orcid.org/0000-0001-8438-6622

Invitamos al interesado a leer el discurso realizado por el presidente Hipólito Yrigoyen ante el Congreso Nacional el 16 de octubre de 1920. Siendo éste muy útil para comprender su pensamiento y reafirmar una vez más la necesidad de la defensa de nuestros recursos.

Don Hipólito no ha sido un personaje muy aficionado a los discursos, por eso son escasos a los que podemos recurrir para estudiar sus posicionamientos. En esa inteligencia, resulta conveniente la lectura del presente a fin de comprender sus acciones e ideas. Máxime si quisiéramos desandar el por qué se dice, fue el primer gobierno nacional y popular elegido democráticamente, gracias a la sanción de la ley Sáenz Peña (Ley $\mathrm{N}^{\mathrm{o}}$ 8.871).

A través de la mencionada ley, en las elecciones del 2 de abril de 1916 Yrigoyen fue electo presidente y Luna Vicepresidente con los votos de 152 electores -recordar que en aquel momento existía el Colegio Electoral, organismo encargado de elegir al Poder Ejecutivo, a través del sufragio indirecto-. En tanto en lo que respecta al poder legislativo, el radicalismo

\footnotetext{
Docente de La matéria Historia Constitucional de la carrera de Abogacía en la Facultad de Ciencias Jurídicas y Sociales de la UNLP.
} 
logró obtener 45 diputados, contra 70 opositores, y 4 senadores contra 26 opositores. De modo que dicha fuerza política obtuvo minoría en ambas cámaras. En diputados recién en la siguiente elección obtuvo la mayoría, sin embargo, en el Senado no ocurrió lo mismo.

Este panorama, sumado a la primera guerra mundial desatada en 1914, nos ilustra de la dificultad que tuvo el primer gobierno radical para gobernar e introducir reformas al Estado, presidido ininterrumpidamente hasta el ' 16 , por la oligarquía terrateniente.

El radicalismo mostró una concepción nacional y una clara intervención del Estado en algunos aspectos de la economía, a modo de ejemplo: la limitación de la renta agraria, el petróleo en manos nacionales, la política ferroviaria, etc, situación que le costó ataques, ruptura del propio partido (personalistas y antipersonalistas) y, finalmente el derrocamiento del poder por medio de un golpe de estado, el 6 de septiembre de 1930.

Podemos observar en el presente discurso, la intervención estatal en la economía, la clara intención que los ferrocarriles sean manejados por la Argentina, y no por compañías foráneas, aunque sea en un formato mixto, en pos de lograr el fomento de las zonas más subyugadas. Lo que Yrigoyen destaca es el concepto de la 'solidaridad nacional', criticando que la ley sancionada dejaba a las poblaciones y regiones subordinadas a los parámetros de rentabilidad de las empresas privadas, contrario a la lógica de que el Estado impulsaba las obras ferroviarias y mantenía en operación ferrocarriles en aquellas regiones que no interesaban a los capitales particulares. En ese orden de ideas, es que Yrigoyen veta la ley que autorizaba el traspaso de los mismos, mediante las facultades que le otorgaba la constitución nacional.

La preocupación del líder radical por la cuestión ferroviaria es clara. La estructura del tendido ferroviario en forma de abanico y finalizando en el puerto, era un claro signo de una economía semi-colonial, lo que permite entender el por qué del 
énfasis en vetar la ley del congreso para pasar líneas férreas a compañías extranjeras.

Así lo señalaba en "Historia de los Ferrocarriles Argentinos" Raúl Scalabrini Ortiz: "Desgraciadamente, las lineas férreas no fueron tendidas con un criterio de equilibrio y unificación nacional (...) Las lineas fueron trazadas con un sentido ajeno a las conveniencias nacionales, porque su estudio, planeamiento $y$ financiación fueron ofrecidos a los extranjeros por razones ajenas a la politica ferroviaria y a la capacidad financiera de la República. Con el correr de los años y el aumento de la riqueza, fue acrecentándose y extendiéndose, hasta constituirse en un poder dotado de armas más eficaces que el mismo gobierno nacional. El ferrocarril extranjero extendió el área comercialmente cultivable con cereales y el perimetro de las praderas aprovechables para la cría de ganado, pero impidió sistemáticamente el comercio interior y las industrializaciones locales. El ferrocarril fue el arma primordial de que se valieron los extranjeros para sofocar todo progreso que de alguna manera pudiera hacer vacilar su hegemonía. Fueron, los nuestros, ferrocarriles coloniales destinados a mantenernos en la rutina sin salida del primitivismo agropecuario" (1975:18).

Lo que Yrigoyen comprende es la importancia de una línea férrea con salida al pacífico. Se repite la misma historia de trabas, idas y venidas. Ello nunca se lograría con los ferrocarriles en manos extranjeras. Por lo que no solo veta la ley del traspaso, sino que presenta un proyecto en ese mismo año para llevar a cabo una serie de obras públicas destinadas a las regiones postergadas y a afianzar las comunicaciones con países vecinos como Chile y Bolivia, tras contar con acuerdos diplomáticos firmados con ambos países para conectar los ferrocarriles entre sí. Como asimismo retomar la construcción de líneas de fomento suspendidas a mediados de la década anterior y demás obras propuestas. Sin embargo como era de esperar dichos proyectos fueron rechazados por el Senado, conformado en su mayoría por conservadores. 
En síntesis lo objetivos de la política ferroviaria delineados por el primer gobierno de Yrigoyen pueden clasificarse en: el fin de los planes de venta o arrendamiento de las líneas del Estado a partir del veto presidencial de 1920; el proyecto de acceso de los Ferrocarriles del Estado a la ciudad de Buenos Aires que era muy rentable y se encontraba bajo exclusiva explotación privada, y el extenso plan de obras ferroviarias, que Alvear ratificó al impulsar la aprobación legislativa que no logró Don Hipólito.

El líder radical comprendió que los Ferrocarriles Estatales eran un resorte estratégico, y que cumplían con la función social de atender con el servicio de transporte a las regiones más apartadas del país, caracterizado por la pobreza y la baja integración a los mercados mundiales.

Es por esa lucidez y empeño en dicha defensa, que hacemos este pequeño comentario, para reivindicar una vez más los intereses nacionales.

\section{Discurso: Irigoyen y su preocupación por ley de privatización de ferrocarriles del Estado}

Discurso que Yrigoyen pronunciara ante el Congreso el 16 de octubre de 1920, preocupado por la sanción de una ley de privatización de los ferrocarriles del estado que perjudicaría a pueblos alejados. Fomentaba, en cambio, una participación por parte del estado "cada día más preponderante en las actividades industriales" y una explotación estatal "de fuentes naturales de riqueza, cuyos productos constituyen elementos vitales del desarrollo general del país".

Buenos Aires, 16 de octubre de 1920. Al Honorable Congreso de la Nación: Tengo el honor de dirigirme a $\mathrm{V}$. Honorabilidad, observando la ley $n^{\circ} 11106$, en uso de la facultad que acuerda al Poder Ejecutivo, el artículo 72 de la constitución nacional. 
La sanción de V.H., subordina todo el plan de la ley a la organización de una compañía privada, que deberá recibir en propiedad la red actual de los denominados ferrocarriles nacionales, constituida por las lineas denominadas "Central Norte Argentino", "Formosa a Embarcación" y "Metán a Barranqueras", y sobre esa base negociar la fusión con la red del Ferrocarril Central Córdoba, Ferrocarril Córdoba y Rosario y Ferrocarril Central-Extensión a Buenos Aires, formando así una compañia por acciones que se denominará "Ferrocarriles Nacionales".

Antes de entrar al estudio analitico de esa organización, cuya sola financiación nos llevaría fatal e inevitablemente a perder no sólo el dominio de los ferrocarriles del estado, sin compensación alguna, sino el contralor de las tarifas de las empresas particulares, defensivo de la economía del país, tan necesario para el desenvolvimiento de sus riquezas, el Poder Ejecutivo debe reafirmar principios fundamentales, que ya be tenido oportunidad de enunciar, y que informan su criterio y definen lo que constituye su politica en materia ferroviaria $y$ en todas aquellas actividades industriales afines con los servicios públicos, o que tiendan a mantener en poder del estado la explotación de fuentes naturales de riqueza, cuyos productos constituyen elementos vitales del desarrollo general del país, en los múltiples aspectos que señalan los progresos de la vida moderna.

Afirma así el Poder Ejecutivo, como fundamental al desenvolvimiento social, político y económico de la nación, el principio del dominio de los ferrocarriles del estado y de la extensión de sus líneas.

Esa orientación de gobierno es la única que responde a los grandes sacrificios realizados por la nación para construir y conservar su red ferroviaria y cualquier 
combinación que nos llevara a fusionar nuestro sistema actual, haciendo participe a cualquier otra compañia como asociada del estado, resultaría siempre en beneficio exclusivo de la compañía particular, dado que las lineas complementarias a construirse del sistema de los ferrocarriles del estado, son las destinadas a proporcionar un tráfico intenso, sirviendo las zonas más ricas de la república y dando salida por el litoral, al interior y al norte, con grandes ventajas económicas en la explotación de sus fuentes naturales de riqueza. (...)

Los ferrocarriles del estado fueron recibidos por el Poder Ejecutivo en una situación de desquicio, despilfarro y perversión tal, que le han demandado grandes esfuerzos tendientes a su mejoramiento y reorganización.

Dentro de un concepto general de gobierno, aceptado por las naciones más progresistas, que se confirma $y$ acentúa cada vez más en la actualidad del mundo, el estado debe adquirir una posición cada día más preponderante en las actividades industriales que respondan principalmente a la realización de servicios públicos y si en alguna parte esas actividades deben sustituirse en lo posible a las aplicaciones del capital privado, es en los países de desarrollo constante y progresivo como el nuestro, donde el servicio público de la naturaleza del que nos ocupa, ha de considerarse principalmente como un instrumento de gobierno con fines de fomento y progreso de las regiones que sirven.

Si hubiéramos, entonces, de aceptar la tendencia que define la sanción de V.H., tendríamos que renunciar a considerar el ferrocarril como un medio de impulsar el desarrollo de la vida económica de ciertos estados de la república con detrimento evidente de una esperanza de mejoramiento, tendríamos la seguridad de su subordinación a las exigencias, siempre crecientes del capital privado, que trata, por definición, de ser retribuido en la forma más amplia. No habrían, entonces, 
la posibilidad siquiera de llenar el fin primordial a que debe responder la ley de que se trata, dentro del concepto de solidaridad nacional a que ella debe tender, desde que volveríamos a las horas aciagas que le ha tocado vivir al país bajo el régimen de las concesiones garantidas, que en sus abusos lo llevaran al borde de la ruina, retardando por muchos años el desarrollo de sus grandes progresos.

Entrando al concepto de la financiación que la sanción de V.H., plantea, el Poder Ejecutivo, debe dejar bien establecido que la forma ideada para la organización del capital a emplearse, con el interés que se fija a las obligaciones y el que devengue durante el período de construcción con la bipoteca de las líneas, sería tan oneroso para los intereses que tiende a servir, que baría imposible el desarrollo, en condiciones favorables, de las zonas comprendidas en el plan de construcción que la misma sanción dispone, gravitando sobre las rentas generales los considerables déficit que esa explotación impondría para que un día el estado, cuya garantía subsidiaria se establece en esa financiación, se vea obligado a entregar esa pare de su valioso patrimonio a la explotación privada, sin defensa posible de las regiones de la república servidas por esas líneas.

El plan del Poder Ejecutivo, expresado oportunamente a V.H., y sobre el cual la H. Cámara de Diputados se pronunció unánimemente en su favor, es el que verdaderamente consulta las posibilidades de llevar a cabo el programa de construcción de obras públicas para responder a los fundamentales intereses de las provincias, que dichas obras públicas tienden a fomentar.

En consecuencia, el Poder Ejecutivo juzga que la ley sancionada por V.H., entraña un verdadero despojo de uno de los primordiales factores de prosperidad del país, como son los ferrocarriles, e implica el retardo $y$ 
acaso el malogramiento del propósito determinante del gobierno en el sentido de llevar lo más rápido posible, todos los beneficios de los ferrocarriles a los pueblos y zonas de la república donde sus riquezas permanece estancadas sin perspectiva de que se las incorpore al desenvolvimiento general de la nación.

El Poder Ejecutivo considera que la sanción de V.H., comportaría un verdadero desastre para la seguridad de los bienes del estado, y el desarrollo progresivo del país, acusando en todo sentido la prolongación de los procedimientos del pasado en vez de la renovación reparadora del presidente.

Hipólito Yrigoyen

Buenos Aires, 16 de octubre de 1920 